\title{
Internet Social Networking
}

\section{Research State of the Art and Implications for Enterprise 2.0}

\author{
Social network sites (SNSs) are a recent success story. Internet social networking refers to \\ the creating, maintaining and interacting with one's social network using Internet \\ technologies, in particular SNSs. SNSs are part of the wider class of social software, which is \\ increasingly being adapted for use in enterprise contexts, such as for connecting employees \\ or improving relationships with customers. The term Enterprise 2.0 has been coined to \\ describe these developments. However, transferring social software with their associated \\ benefits to the corporate context requires a good understanding of the associated user \\ phenomena.
}

DOI 10.1007/s12599-011-0151-y

\section{The Authors}

Daniel Richter (MScIS) $(\bowtie)$

Institut für Wirtschaftsinformatik Lehrstuhl für Wirtschaftsinformatik und Interorganisationssysteme Universität Münster

Leonardo-Campus 3

48149 Münster

Germany

daniel.richter@wi.uni-muenster.de

\section{PD Dr. Kai Riemer}

Discipline of Business Information

Systems Business School

The University of Sydney

Building $\mathrm{H} 69$

2006 NSW

Australia

kai.riemer@sydney.edu.au

Prof. Dr. Jan vom Brocke Hilti Chair of Business Process

Management Institute of Information

Systems

University of Liechtenstein

Fürst-Franz-Josef-Strasse

9490 Vaduz

Liechtenstein

jan.vom.brocke@uni.li

Received: 2010-05-10

Accepted: 2010-12-14

Accepted after two revisions by

Prof. Dr. Buxmann.

Published online: 2011-03-05
This article is also available in German in print and via http://www. wirtschaftsinformatik.de: Richter D, Riemer K, vom Brocke J (2011) Internet Social Networking. Stand der Forschung und Konsequenzen für Enterprise 2.0. WIRTSCHAFTSINFORMATIK. doi: 10.1007/s11576-011-0265-3.

Electronic Supplementary Material The online version of this article (doi: 10.1007/s12599-011-0151-y) contains supplementary material, which is available to authorized users.

(c) Gabler Verlag 2011

\section{Introduction}

Social network sites (SNSs) have gained much attention from the public over the past few years. Since the emergence of the first web sites that supported some form of creating and interlinking of user profiles in the late 1990s (Boyd and Ellison 2007) SNSs have mushroomed (Richter et al. 2009c), and are among the most frequently used sites on the Internet. For example, Facebook as the most prominent example has more than 500 million members ${ }^{1}$ and is the second most visited website $^{2}$ on the Internet. The main aim of SNSs is to facilitate relationships with acquaintances, friends, family, or professional contacts. Hence, with the term Internet social networking (ISN) we refer to the phenomenon of building and maintaining one's social network on the public Internet, which mostly occurs on SNSs, but can be interpreted more generally as people can use a range of other services on the Internet to connect with others (Richter et al. 2009c). Our focus for the matter of this paper will be ISN phenomena on SNSs, or more precisely a review of existing research dealing with such phenomena. SNSs are typically seen as part of the wider class of social software and prototype for the development of intranet social network platforms in the context of Enterprise 2.0. Both terms are widely considered in information systems literature (Boyd 2006b; Davenport 2008; Hippner 2006; McAfee 2006b; Richter et al. 2009b). An overview of the terminology used in our study is provided in Sect. 2 (see also Fig. 1).

ISN research is a relatively new field; first works appeared in 2003 and since 2007 the field has gained significant momentum. However, the research landscape remains rather fragmented with ISN research being scattered across several communities and with many different aspects of ISN having been researched. Only very few articles have tried to conceptualize the phenomenon and its manifestation on SNSs. A coherent understanding of what typically accounts for ISN research issues is yet to emerge.

\footnotetext{
${ }^{1}$ http://blog.facebook.com/blog.php?post=409753352130.

${ }^{2}$ http://www.alexa.com/siteinfo/facebook.com.
} 
Fig. 1 Positioning of Enterprise 2.0, Internet social networking, and corresponding technologies

\begin{tabular}{|c|c|c|c|}
\hline Scope & & Public Internet & Enterprise Contexts \\
\hline \multirow{2}{*}{$\begin{array}{l}\bar{\pi} \\
\frac{\pi}{0} \\
\frac{c}{0} \\
0\end{array}$} & Phenomenon & Web 2.0 & Enterprise 2.0 \\
\hline & Artefact & $\begin{array}{l}\text { Social Software } \\
\text { Platforms }\end{array}$ & Intranet Social Software \\
\hline \multirow{2}{*}{ 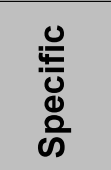 } & Phenomenon & \begin{tabular}{|l|} 
Internet Social \\
Networking (ISN)
\end{tabular} & \begin{tabular}{|l|} 
Enterprise Social \\
Networking (ESN)
\end{tabular} \\
\hline & Artefact & $\begin{array}{l}\text { Social Network Sites } \\
\text { (SNS) }\end{array}$ & $\begin{array}{l}\text { Intranet Social Network } \\
\text { Platforms }\end{array}$ \\
\hline
\end{tabular}

Against this backdrop, we want to 1) give an overview of existing research and take stock of what has been achieved in order to promote a stronger conceptualization of the phenomenon of ISN. Furthermore, we want to 2) make accessible the existing body of ISN-related research for researchers as well as practitioners engaged in theorizing or facilitating SNSbased social networking in the context of Enterprise 2.0.

Enterprise 2.0 as a concept subsumes the efforts of adopting social software, originating from the public Internet, for use in enterprise contexts and for professional purposes (McAfee 2006b). However, as the social software phenomenon is very closely connected to the unique culture of user participation and bottom up emergence typical for Web 2.0 (see O'Reilly 2005), transferring the phenomenon from the public Internet to the corporate context requires a good understanding of the phenomenon and its manifestation in different technical platforms. We believe that a better understanding of the phenomenon of ISN on the public Internet can lead to conclusions that can usefully inform the deployment and adoption of SNSs for enterprise usage. We will refer to the phenomenon of SNS-based social networking in enterprise contexts as Enterprise Social Networking (ESN).

Our paper proceeds as follows. We start by defining key terms. In section three we present an overview of our study. We then identify key research areas that structure the field of ISN research to date; moreover, we review in more detail some key contributions in each of the areas and discuss the current state of research as well as implications for future work. In section five we emphasize the potential of SNSs in an enterprise context in the light of our literature review. We conclude the paper with a short summary.

\section{Social Network Sites, Definition, and History}

In order to introduce the concept of ISN, we will first provide working definitions of relevant concepts we use in our study, as to date the terminology of concepts relevant to ISN research appears to be rather diverse. We then give a brief insight into the short history of this emerging field.

\subsection{Key Concepts}

\subsubsection{Internet Social Networking}

ISN refers to the phenomenon of social networking on the Internet. As such, the concept subsumes all activities by Internet users with regard to extending or maintaining their social network. Social network theory further characterizes the concept (Carton and Wellman 1999): a social network is defined as a set of individuals who establish with each other links of some kind, such as acquaintance or friendship (Newman 2003). As such, the individuals and their activities in the social network are interdependent and the linkages are channels for transfer of immaterial resources (Wasserman and Faust 1994). It becomes obvious that ISN is a general phenomenon, which can materialize in many ways and facilitated through a range of technologies. In this paper, we focus on ISN as a phenomenon, but only in the context of SNSs as the technological basis.

\subsubsection{Social Network Sites}

Boyd and Ellison define SNSs as "webbased services that allow individuals to (1) construct a public or semi-public profile within a bounded system, (2) articulate a list of other users with whom they share a connection, and (3) view and traverse their list of connections and those made by others within the system. The nature and nomenclature of these connections may vary from site to site" (Boyd and Ellison 2007, p. 211). Typical examples for such sites are Facebook, MySpace, XING, StudiVZ etc. Please note that some have criticized this definition as being too broad (Beer 2008), since it might include web sites that feature the above characteristics in addition to different sets of core features. Examples of web sites that exhibit certain SNS features, but are not strictly SNSs are Youtube, Twitter, or Flickr. In this paper however, we refer to SNSs as services that have the facilitation of ISN as their core purpose.

\subsubsection{Social Software}

SNSs are one type of what has been termed social software (Bächle 2006; Boyd 2006b; Hippner 2006). Wikis, microblogging, and social bookmarking services are other types of social software. In an enterprise context, feature-wise, social software is closely related to groupware (Groß and Koch 2007), but is often portrayed as being applied and used in a "bottom up" instead of a "top down" approach (Avram 2006), as users generate the content and define the rules and reasons for usage (Boyd 2006b). As such, social software subsumes tools in the context of the larger phenomenon of Web 2.0 (Boyd 2006b; Hippner 2006; O’Reilly 2005). Another difference to groupware is that social software originates from the public Internet, where the tools emerged and evolved, shaped heavily by its users, while groupware typically refers to software that has been designed to support deliberately the interactions of people in enterprise work groups.

\subsubsection{Enterprise 2.0}

The term Enterprise 2.0 describes the adoption of social software in an enterprise context. Much as ISN denotes the 
phenomenon and refers to the application of SNS as its main enabling technologies, Enterprise 2.0 refers to the phenomenon of a new participatory corporate culture (with regard to communication and information sharing), which is based on the application of various types of social software technologies. The term Enterprise 2.0 was coined by Andrew McAfee (2006a, 2006b). McAfee defines Enterprise 2.0 as "the use of emergent social software platforms within companies, or between companies and their partners or customers" (McAfee 2006a).

Enterprise 2.0 is not just about applying social software, but it describes a wider approach that advocates a new culture of participation, inclusion, and sharing. From a management perspective Enterprise 2.0 therefore is as much about implementing new IT artifacts as it is about managing corporate communication structures (Koch and Richter 2007). Henceforth, it will be necessary for research in this domain to aim to better understand the rich set of challenges around applying social software, such as SNS, in an enterprise context in order to help derive strategies to exploit its potentials, while addressing potential change issues at the same time.

\subsubsection{Enterprise Social Networking}

ESN refers to the phenomenon of social networking in an enterprise context. As such, we can differentiate between two different types of ESN based on the actors that are involved. Firstly, ESN refers to social networking on intranet social network platforms, ${ }^{3}$ which can functionally be compared to SNSs, but are only accessible in the enterprise intranet. Hence, the set of individuals is restricted to employees of an enterprise and the links mostly reflect professional relationships. Secondly, ESN subsumes phenomena of enterprise usage of public SNSs. Examples are company pages on Facebook, where interaction takes place with potential customers, and the usage of business related SNSs (e.g., LinkedIn) for recruiting.

\subsection{A Brief Look at History}

The first Internet site, which resembled what we perceive as SNSs today, was SixDegrees (Boyd and Ellison 2007). However, the first of the modern SNSs that had notable success was Friendster, which was founded in 2002 primarily to serve as a dating site. But just when it seemed that Friendster could attract a wider audience, technical issues and management mistakes hampered its further diffusion (Boyd 2006b). Soon after, MySpace was founded and took over many users earlier attracted by Friendster. Then, between 2003 and 2004, most SNSs that are popular today were founded, such as LinkedIn, Facebook, or Xing. ${ }^{4}$

Today, thousands of SNSs exist (Richter et al. 2009c). Besides the popular generalpurpose SNSs like Facebook and MySpace, the market for SNSs is populated by all kinds of very specific SNSs, some of which target very specific user groups with only few hundred users or even less. Today, the dominant site in the market is Facebook; its user base exceeds 500 million, in contrast to the 130 million users on MySpace as the next biggest player. With Facebook now lacking an even competitor it seems to be heading for a monopoly-like position.

With the major share of the market being dominated by a handful of SNSs it appears essential for newly established SNSs to concentrate on niches and more focused business models. Examples for such services are Ning, Audimated, and Folksdirect. Ning for example is a service provider offering to host various third party SNSs, while Folksdirect promises to offer a privacy-focused environment. How these smaller players will fare in the market is not yet foreseeable. A timeline of SNS market appearances is displayed in Fig. 2.

\section{Literature Review}

ISN research as a domain is still relatively young; to our knowledge, the first publication explicitly dedicated to ISN dates back to 2003. Since then a significant body of research has been created. One of the most cited articles in the field is a literature review by Boyd and Ellison (2007), which provides an overview of the early years of research in the domain. Boyd and Ellison illustrated the diversity of research in singling out certain publications and research findings. Moreover, they framed the research field by providing relevant definitions. But since research studies have mushroomed in the past two years in particular, significantly enriching and broadening the research spectrum, we believe it is time for providing an updated overview of ISN research. Indeed most of the articles we found in our literature search process stem from the period 2008 to 2009. This justifies taking a detailed look at the research field again, analyzing what has been achieved as well as what might be missing.

In doing so, our literature review aims to identify and describe the state of the art of research on ISN on SNSs, as a basis for identifying future research directions for the field (vom Brocke et al. 2009b). By doing so, we also want to foster and build new ground for comparative literature reviews on ISN by making accessible knowledge that has already been created but also highlighting areas where research is missing. Furthermore, we will elicit implications for enterprise contexts.

\subsection{Sampling: Selection of Literature Sources}

The timeframe for our literature review comprises the years 2003 to 2009. The first starting point for identifying literature for inclusion in the study was the above-mentioned literature review, as well as an associated literature list, which one of the authors is maintaining on her website. ${ }^{5}$ We then carried out a full literature search on every journal that appeared in these sources. Moreover, we included the main journals in the field of Information Systems and the proceedings of the main international and European conferences (ICIS and ECIS) in our literature search. Where possible we tried to search in the full-text articles; for all databases we searched in the abstracts using the following search terms: social networking, social network site and social network service. Depending on the functionality of the search engine we used different forms of string concatenations. ${ }^{6}$

\footnotetext{
${ }^{3}$ Examples for intranet social network platforms are Jive (http://www.jivesoftware.com/) and Lotus Connections (http://www-142.ibm.com/ software/products/de/de/connections/).

${ }^{4}$ For a more detailed description of the history of SNSs until 2007 please see (Boyd and Ellison 2007).

${ }^{5}$ http://www.danah.org/researchBibs/sns.html.

${ }^{6} \mathrm{~A}$ detailed description of the search process following the guidelines by vom Brocke et al. (2009b) is presented in the Online Appendix.
} 


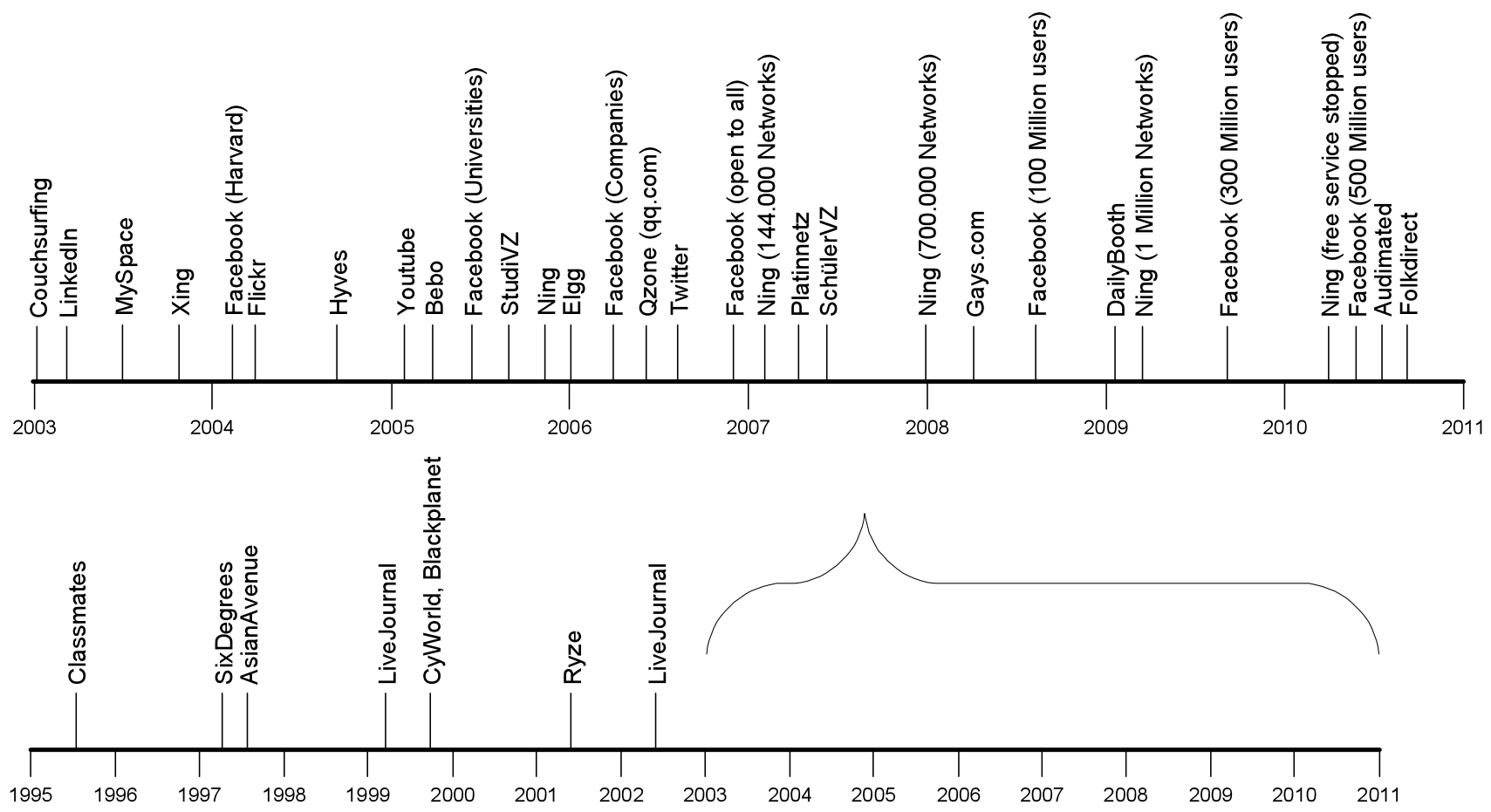

Fig. 2 SNSs history

Table 1 Important Publication Sources included in the review ${ }^{7}$

\begin{tabular}{|l|r|}
\hline \multicolumn{1}{|c|}{ Journal } & \#ublications \\
\hline \hline First Monday & $\mathbf{2 0}$ \\
\hline \hline Journal of Computer-Mediated Communication & $\mathbf{1 8}$ \\
\hline \hline CyberPsychology \& Behaviour & $\mathbf{1 3}$ \\
\hline \hline Lecture Notes in Computer Science & $\mathbf{9}$ \\
\hline \hline Computers in Human Behaviour & $\mathbf{8}$ \\
\hline \hline Communications of the ACM & $\mathbf{3}$ \\
\hline \hline New Media \& Society & $\mathbf{3}$ \\
\hline \hline Journal of Adolescent Research & $\mathbf{2}$ \\
\hline \hline Information, Communication \& Society & $\mathbf{2}$ \\
\hline \hline Computers and Composition & $\mathbf{2}$ \\
\hline \hline Communication Research & $\mathbf{2}$ \\
\hline \hline Archives of Pediatrics \& Adolescent Medicine & $\mathbf{2}$ \\
\hline \hline American Journal of Pharmaceutical Education & $\mathbf{2}$ \\
\hline \hline European Journal on Information Systems & $\mathbf{1}$ \\
\hline \hline International Conference on Information Systems (ICIS) & $\mathbf{6}$ \\
\hline \hline European Conference on Information Systems (ECIS) & $\mathbf{4}$ \\
\hline
\end{tabular}

It is notable that a large number of publications appear in a relatively small number of Journals (see Table 1), with most of the highly ranked journals in the Information Systems field not yet among them. One reason for this may be that the research field is not yet mature enough to identify findings that yield general, theoretical contributions to the Information

\footnotetext{
${ }^{7}$ Only Journals are listed that contained relevant articles. In total 37 journals have been searched including the major IS journals (AIS senior scholars' basket of eight). A complete list can be found in the Online Appendix.
} 


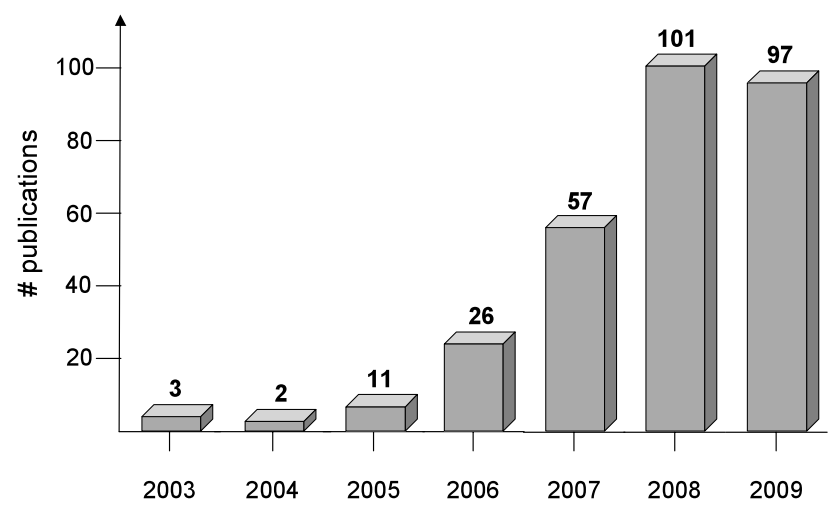

Fig. 3 Distribution of publications over time

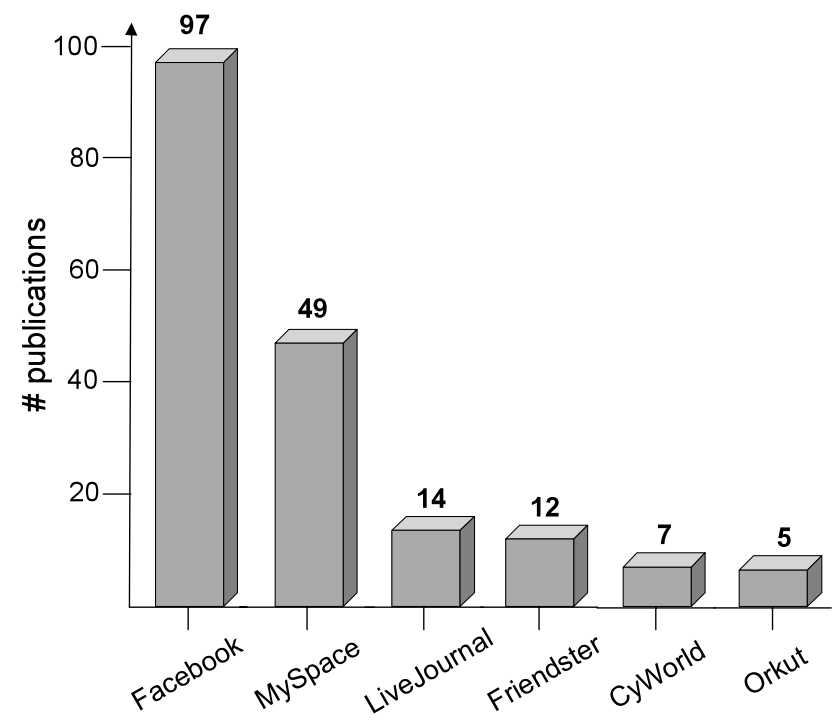

Fig. 4 Distribution of publication by social network sites

Systems field, which would be of broader value, or simply that the review process of these journals is too long to have resulted in publications yet. In our analysis we point to and reason on evidence of why they have not found their way into the Information Systems mainstream literature just yet.

\subsection{Overview of the Identified Literature Sample}

In this section we take a brief look at the nature of ISN research found in our sample. In total, we have identified 297 papers over a time span of seven years that deal with topics in the context of ISN. Fig. 3 displays the number of publications over time, highlighting its strong growth until 2008.

Of the 297 identified publications 202 publications were included in the review. The remaining 95 publications either deal with ISN in a broader sense, e.g., on other websites (like weblogs), technical design issues of SNSs or social network analysis. They do not refer to or explain aspects of ISN on SNSs and are hence omitted. Most of the remaining 202 publications are either empirical studies focusing on one SNS or on a group of SNSs, with studies on one SNS far outnumbering those looking at more than one SNS (130 to 35). Among those SNSs by far the most studies concentrate on either Facebook or MySpace. Other SNSs appear to be marginalized in the existing body of research (cf. Fig. 4).

Finally, twenty publications - ten percent - take a theoretical view on ISN. Those papers that use a theory to frame their research most often use social capital theory, which is used in five studies. Other theories, such as transaction cost theory or signaling theory, are used only occasionally. This is another indication that the research field is still young, with most papers evolving around de- scribing or explaining the technology or various facets of the phenomenon, but not yet theorising in more general terms. In the following section we discuss in detail those areas of research we identified in our literature analysis.

\section{Streams of Research on Internet Social Networking}

As a result of our literature review, we identified four streams of research that look into various aspects of the ISN phenomenon: 1) Personal information disclosure and user privacy, 2) Nature of links and the role of the personal social network, 3) User self-presentation and impression management, and 4) User motivations for adopting and using SNSs. We present our findings according to these subject areas. The order of presentation reflects the number of studies in the respective areas, with user privacyrelated studies accounting for the majority in our sample. A summary of our main findings in the four areas is presented in Table 2 .

\subsection{Personal Information Disclosure and User Privacy}

The idea of ISN on SNSs centers around users creating semi-public profiles and the ability to browse these profiles (Boyd and Ellison 2007). Therefore - by their very nature - SNSs are designed to capture, store, and make available personal information. Consequently, while the information revealed in personal profiles is one of the main value propositions of SNSs, at the same time it poses a significant potential for misuse (Livingstone 2008). Not surprisingly, with the beginning of their wider diffusion during 2005 and 2006 privacy issues soon started to dominate ISN research. In general, research into user privacy on SNSs focuses on Facebook and MySpace. While about half of the studies looked at Facebook exclusively, two-thirds included Facebook among others. As Facebook has its roots and most dominant user population in the United States, and given the fact that students and youth were the first to adopt the service (Lenhart and Madden 2007), privacy-related research seems to be of special interest to the US community (Barnes 2006).

In 2005, Gross and Acquisti (2005) were among the first to highlight typical privacy issues associated with the use of 
Table 2 Overview of key findings in ISN research

\begin{tabular}{|c|c|c|}
\hline \multicolumn{2}{|c|}{ Streams of Research } & Key Findings \\
\hline 1 & $\begin{array}{l}\text { Personal } \\
\text { information } \\
\text { disclosure and } \\
\text { user privacy }\end{array}$ & $\begin{array}{l}\text { - SNS users have become more careful about revealing personal } \\
\text { information } \\
\text { - Young users seem to control their information disclosure by adjusting } \\
\text { profile visibility }\end{array}$ \\
\hline 2 & $\begin{array}{l}\text { Nature of links } \\
\text { and the role of } \\
\text { the personal } \\
\text { social network }\end{array}$ & $\begin{array}{l}\text { - Differences exist on how friendship links establish and are perceived on } \\
\text { SNSs } \\
\text { - online vs offline relationships } \\
\text { - importance of the size of the personal network } \\
\text { - nature and role of relationships } \\
\text { - The influence of social norms and cultural backgrounds in this is not } \\
\text { understood yet }\end{array}$ \\
\hline 3 & $\begin{array}{l}\text { User self- } \\
\text { presentation } \\
\text { and impression } \\
\text { management }\end{array}$ & $\begin{array}{l}\text { - SNS users seem to execute similar strategies for utilizing relationships for } \\
\text { impression management online and offline } \\
\text { - Impression management is not limited to profile design } \\
\text { - friends list is used to generate attention and prestige } \\
\text { - blackboards and testimonials are used to co-form identities } \\
\text { - Relationship to close friends is perceived as the most trustworthy } \\
\text { information } \\
\text { - Notable differences seem to exist concerning impression management on } \\
\text { different kinds of SNSs }\end{array}$ \\
\hline 4 & $\begin{array}{l}\text { User } \\
\text { motivations for } \\
\text { adopting and } \\
\text { using SNSs }\end{array}$ & $\begin{array}{l}\text { - Main motives for Facebook usage seem to be } \\
\text { - Staying in contact } \\
\text { - Finding out more about new offline contacts } \\
\text { - The facilitation of gossip } \\
\text { - Little research exists dealing with other SNSs or the motives of adult users }\end{array}$ \\
\hline
\end{tabular}

SNSs; they analyzed 4000 Facebook profiles and pointed out the potential harm that could be caused by information disclosed therein. At the time, research into the topic quickly began to grow, as did public awareness of the topic. Interestingly, research findings point to an evolution of user awareness of the topic and changes in behaviour over the past years.

Early studies revealed that especially young SNS users seemed to be relatively unconcerned, if not unaware, of potential pitfalls (Acquisti and Gross 2006; Stutzman 2006). Barnes at the time reasoned that "often teens are not aware of the public nature of the Internet" (Barnes 2006). However, more recent studies reveal that SNS users, the more experience they gain with ISN, the more they become careful about revealing personal information (Lewis et al. 2008). Moreover, it seems that awareness for the privacy topic is growing (Christofides et al. 2009).

Further studies have investigated how users react to the privacy challenges. For example, younger users, such as students and adolescents, seem to control their information disclosure by adjusting profile visibility rather than by reducing the information disclosed on their profiles (Tufekci 2008). Other studies found that users are more active today and exhibit increasing control over their information disclosure (Hinduja and Patchin 2008; Jones et al. 2008). Consequently, Ybarra and Mitchell (2008) show in a study with 1588 young people that SNSs are a less risky environment for sexual harassment than chat and instant messaging. Nevertheless, SNSs disclose more personal information than any other service before. Facebook alone hosts personal information on more than 500 Million individuals. Even though recent studies have not found SNSs to be a more risky environment than the Internet in general, the sheer amount of data does imply a risk for misuse. Research has to further investigate how personal data on SNSs can be secured as well as where concrete potential for misuse exists, with one of the concerns being that the platform provider itself exhibits a strong interest in using its users' information for various commercial purposes. ${ }^{8}$

\subsection{Nature of Links and the Role of the Personal Social Network}

The second stream of ISN research looks into the nature and proliferation of relationships and social networks within SNSs. In doing so, studies have shown that users inscribe different meaning to their links with other SNS users. Specifically, studies have revealed that 1) dif- ferences exist between online and offline relationships, 2) the size of the personal network is judged quite differently on different platforms, and 3) notable differences exist between the nature and role of relationships and personal social networks on different platforms (e.g., links in Facebook and MySpace are perceived rather differently). Such differences are likely to result from differences in group culture and the social micro environment on these platforms.

What accounts as friendship offline is not necessarily the same as having friends online (Boyd 2006a). For example, a significant share of users on MySpace and Bebo appears to collect "friends" in order to improve the impression made by their own profile (British Office of Communication 2008; Rosen 2007), with having more friends being regarded beneficial. In contrast, on other SNSs, such as Facebook or CyWorld, the online social network seems to reflect better the users' offline networks (Chun et al. 2008; Lampe et al. 2006; vom Brocke et al. 2009a). In fact, studies have shown that contrary to MySpace, having too many links on Facebook can have a negative reputation effect as this reportedly lessens the perceived trustworthiness of a user profile (Tong et al. 2008).

\footnotetext{
${ }^{8}$ E.g., http://www.guardian.co.uk/business/2009/feb/01/facebook-seeks-to-exploit-user-information.
} 
Moreover, no consistent interpretation exists of what accounts as friendship online (Fono and Raynes-Goldie 2006). However, it has been shown that social norms, which regulate the articulation of relationships, can differ significantly between social groups (cf. British Office of Communication 2008; Rosen 2007). Such differences are likely to cause the emergence of SNS usage patterns specific to those social groups. And while many smaller SNSs exist, which target certain social groups with differing cultural backgrounds, to our knowledge almost no studies so far have looked into the influence that social norms and hence the cultural group background poses on SNS usage. Exceptions are one study by Byrne (2007) on the adoption of the SNS BlackPlanet and a study by Carroll (2008) focusing on the usage of MySpace by Puerto Ricans. Both studies are very focused on specific aspects of SNS usage and create no general understanding of how these SNSs are used or how cultural differences influence adoption and use. Hence, to date we have no clear understanding of how strong the influence of different social norms and cultural backgrounds on the adoption of SNSs is.

\subsection{User Self-Presentation and Impression Management}

The third stream of research captures studies that have investigated how users draw on the various SNS features to manage self-presentation and the impressions they leave with other users, as well as the effects thereof. Impression management commonly refers to methods or strategies with which people try to influence the impressions others hold about them (Goffman 1959). In this important strand of ISN research, studies have looked at various aspects of impression management, such as 1) the nature of and differences between self-presentation online and offline, 2) how users draw on various SNS features in going about their impression management, 3) what the effects are of 'good' self-presentation, and 4) differences in user self-presentation between platforms and vis-à-vis different user groups.

The first publication to mention impression management appeared in 2004 (Donath and Boyd 2004). According to the authors, SNS users seem to execute similar strategies for utilizing relationships for impression management online and offline. Similarly, Dwyer (2007) found in her qualitative study that individuals seem to execute one strategy of impression management and apply this strategy in all communication channels they are using. Studies comparing impression management on Facebook and offline also reveal strong similarities (Buffardi and Campbell 2008; Evans et al. 2008; Gosling et al. 2007). However keeping in mind the different nature of SNS usage observed on sites like MySpace (i.e. Rosen 2007) this finding is likely to be limited to SNSs that reflect a real world context like Facebook (see above).

Interestingly, user impression management is not limited to 1) actively creating one's user profile but also includes 2) friendship links and 3) page content, e.g., comments on one's blackboard left by other users. At the same time however, researchers acknowledge that in managing impressions users have more immediate control over their own profile information; therefore this information can better describe how a person wants to be perceived (Zhao et al. 2008) or what the person is looking for online. Lampe et al. (2007) revealed in a qualitative study on Facebook that the detail level of profiles correlates with the number of online friendship links. They argue that those profile elements that help identify common interests or similarities in background help foster the creation of new friendships.

However, some users attempt to present online an ideal self that is too good to be true (Zhao et al. 2008). This stretching of the truth can reach a level where other users perceive it as outright lying (Session 2009). On some SNSs lying about oneself seems to have formed a common pattern (British Office of Communication 2008). Consequently, probably due to the risk of being lied at, profile information is not perceived as particularly trustworthy.

Moreover, by using blackboards and testimonials other users also participate in the evolution of one's profile as they help co-form one's presented identity (Boyd and Heer 2006). Lee and Bruckman (2007) analyzed the dating behavior of individuals on SNSs and found that both the friends listed as well as the conversations with close friends play a vital role in the search for a potential partner. This corresponds with studies on the perceived attractiveness of SNS users, which looked at various influence factors of selfpresentation (Walther et al. 2009, 2008).
The relationship to close friends is perceived as the most trustworthy information.

Most of the above-presented work on impression management stems from analyses on the usage of Facebook, MySpace, or Friendster. Very few studies also deal with other SNSs like Xing or Lunastorm. In comparison, these studies reveal notable differences in the practices of impression management. For example strategies of impression management are executed more carefully on businessoriented SNSs such as Xing (Schaefer 2008), as users concentrate less on gaining attention and more on making a trustworthy impression to potential employers and business partners. On the other hand, Facebook usage is much more playful than that of Xing, but still fairly accurate (Evans et al. 2008; Zhao et al. 2008), while MySpace is even more playful yet less accurate (Rosen 2007). While impression management has been well-researched in the core target group of students and youth, little understanding exists about what and how strategies for managing self-presentation work effectively in other social groups or even a business environment.

\subsection{User Motivations for Adopting and Using SNSs}

Another strand of research has looked into user motivations for adopting SNSs. However, while there have been a number of studies in this field, almost all of them have looked into SNS usage among (university) students. Moreover, existing research seems to be fairly fragmented.

Krasnova et al. (2008), by applying human needs theory, have found that the need for belongingness through connection with others and esteem needs through self-presentation are two important drivers for SNS usage. Bumgarner points out that Facebook is used by students to stay in contact with old friends, to get in contact with co-students, romantic partners or similar, but that most prominently Facebook is used to facilitate the exchange of gossip (Bumgarner 2007). Other studies have revealed the maintenance of contacts with old friends and the intensification of links to costudents as the two main motives for using SNSs (Lampe et al. 2006; Raacke and Bonds-Raacke 2008; vom Brocke et al. 2009a). Lampe et al. refer to the latter motive as the need for social searching, which constitutes an important usage pattern for students. Social searches 
Table 3 Suggested directions for general research on ISN

\begin{tabular}{|c|c|c|}
\hline & Broaden the empirical basis & Comparative research \\
\hline 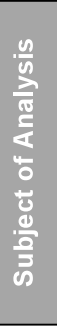 & $\begin{array}{l}\text { Empirical research has to be conducted in } \\
\text { order to overcome the existing constraint } \\
\text { with regards to: } \\
\text { - user groups } \\
\text { - use contexts } \\
\text { - Social Network Sites }\end{array}$ & $\begin{array}{l}\text { The specific focus of ISN research to date } \\
\text { has created a profound basis for in depth } \\
\text { analysis and comparison of e.g. } \\
\text { - Facebook vs. MySpace } \\
\text { - Usage by students vs. young people } \\
\text { Comparative research executed on this } \\
\text { literature base potentially can create an } \\
\text { understanding of the influence of the social } \\
\text { context of use (social norms, cultural } \\
\text { backgrounds, etc.) }\end{array}$ \\
\hline $\begin{array}{l}\text { 흘 } \\
\frac{\circ}{\circ} \\
\frac{0}{0} \\
\frac{0}{0} \\
\frac{0}{2}\end{array}$ & $\begin{array}{l}\text { - Phenomenological research } \\
\text { - Longitudinal studies } \\
\text { - Case studies }\end{array}$ & $\begin{array}{l}\text { Cross-literature research comparing } \\
\text { - The adoption of one SNS in different } \\
\text { contexts (university, ...) } \\
\text { - The adoption of different SNSs (mainly } \\
\text { Facebook vs. MySpace) in the same } \\
\text { context }\end{array}$ \\
\hline
\end{tabular}

utilize the SNS to find out more about newly made offline contacts, such as fellow students one has met in class (Lampe et al. 2006). Others have argued that, as SNSs usage is said to have a positive influence on the emergence of bridging social capital (Steinfield et al. 2008), students utilizing SNSs early in their studies are better integrated into the social network of the university later in their studies (Steinfield et al. 2008). Social searching thus seems to assist an individual in integrating into a new social (offline) environment.

Apart from these studies, which have researched motives for engaging in ISN among students, little research exists on the motives of other user groups. One exception is a study on motives of professional users, which looks at Xing (Schaefer 2008). The study identified three major motives in this context: (1) staying in contact, (2) reactivation of contacts, and most importantly (3) the management of one's existing contact-network.

However, apart from this, to our knowledge no work exists on the motivation of adults using SNSs. Also, existing research almost exclusively focuses on Facebook. This certainly leaves room for future research, especially with a focus on professional users of SNS and their motives.

\subsection{Summary: Current State of Research and Open Questions}

Our literature analysis reveals a significant body of research in the context of ISN on SNSs. We identified some research strands capturing those ISN aspects that have been well-researched. However, the current state of research is not without limitations: 1) Existing research is very much limited to studies investigating SNS usage among students and youth. 2) Not many studies recognize differences between existing SNSs. Many studies treat ISN across SNSs as being homogeneous, while we believe differences exist with regards to technology and typical use practices. 3) Moreover, and partly as a result of the first two limitations, the ISN research landscape remains rather fragmented, since not many studies have attempted to carry out crossliterature research, which aims to draw more general conclusions across use contexts and SNSs. 4) So far, only very few studies, apart from some show case stories, look into the enterprise use of SNSs and how ISN phenomena observed on the public Internet might translate into an enterprise context. We briefly discuss future research opportunities for general ISN research, before we look into implications for enterprise applications.

As mentioned above, most ISN studies concentrate on students or young people, using Facebook or MySpace in the USA. Hence, existing research is constrained with regards to user population, geographical region, and technology artifact. Such limitations are likely to hamper the identification of both more general patterns across different contexts and the specifics of ISN in certain contexts or on other types of platforms.

Our analysis above revealed that the culture of a user group can exert a strong influence on SNS usage (cf. Friendster case in Boyd 2006b and MySpace case in Rosen 2007). Due to the proliferation of ISN among students as early adopters (Facebook originates from this user group) and the easy access to empirical data on Facebook, this combi- nation has been well-researched. Meanwhile however, SNSs have turned into a mass phenomenon permeating a range of user groups. But we know very little about the adoption and use among other groups. Moreover, we also know little about how students continue using SNSs once they make the transition from university into work life.

Furthermore, existing research is very much embedded culturally in a Western context, while some preliminary work suggests that geography plays indeed a very important role in explaining certain adoption and use pattern; see for example the case of the Korean SNS CyWorld (Choi 2006) or the Japanese SNS Mixi (Fogg and Iizawa 2008). But also smaller contextual differences can cause different patterns of adoption like shown in a study on SNS usage among students in Germany and Liechtenstein using Facebook and StudiVZ (vom Brocke et al. 2009a).

To this day, very little work has been undertaken to conceptualize the differences between SNSs (as different artifacts). The existing heterogeneity in the market for SNSs is not reflected in the literature so far (Richter et al. 2009c). Studies including business-oriented SNSs like Xing (Schaefer 2008; vom Brocke et al. 2009a) or LinkedIn (Thew 2008) highlight differences in the adoption of certain features compared to SNSs like Facebook or MySpace. More cross-case research is needed to investigate these differences.

These limitations lead us to propose two major directions for future SNS research, as is displayed in Table 3. On the one hand we propose to broaden the empirical basis by carrying out research across different user groups, use 
Table 4 Suggested

directions for enterprise-related research on ISN

\begin{tabular}{|c|c|c|}
\hline & Potential of SNS usage & Exemplary Future Research Directions \\
\hline 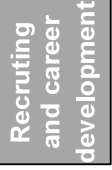 & $\begin{array}{l}\text { - Marketplaces for the exchange of skills } \\
\text { - Advancing career opportunities } \\
\text { - Hire and recruit business professionals }\end{array}$ & $\begin{array}{l}\text { - What renders recruiting activities in SNSs } \\
\text { successful? } \\
\text { - Creation of a systematic understanding of } \\
\text { the potential and role for professional } \\
\text { career development. }\end{array}$ \\
\hline 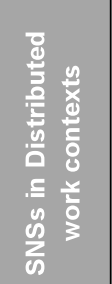 & $\begin{array}{l}\text { - Facilitation of internal network building, } \\
\text { social encounters and group work } \\
\text { - Creation and maintenance of social } \\
\text { structures containing social capital and as } \\
\text { channels for information transfer between } \\
\text { individuals } \\
\text { - Creation of a common basis for } \\
\text { communication even between distant co- } \\
\text { workers }\end{array}$ & $\begin{array}{l}\text { - Under which circumstances will employees } \\
\text { be willing to disclose significant amounts of } \\
\text { data about themselves? } \\
\text { - Can strategies like „Social Searching“ } \\
\text { executed on public SNSs be successfully } \\
\text { adapted for intranet SNSs? } \\
\text { - How can SNSs be successfully integrated } \\
\text { into the IT infrastructure? }\end{array}$ \\
\hline 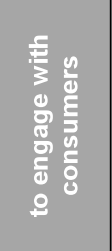 & $\begin{array}{l}\text { - Advertising (by facilitating targeted } \\
\text { approaches and viral marketing) } \\
\text { - Product development (by including } \\
\text { consumers in the design process, i.e. } \\
\text { prosuming) } \\
\text { - Market intelligence (by observing and } \\
\text { analyzing the data generated by users in } \\
\text { SNSs) }\end{array}$ & $\begin{array}{l}\text { - Why did viral marketing on SNSs not live } \\
\text { up to the high initial expectations yet? Will } \\
\text { it do so in the future? } \\
\text { - How are brand pages used? Can they } \\
\text { facilitate prosuming? } \\
\text { - How can SNSs be used for gathering } \\
\text { market intelligence? }\end{array}$ \\
\hline
\end{tabular}

contexts, and SNSs. On the other hand we see a necessity to also carry out crossliterature studies in order to better capitalize on and exploit existing research findings. Based on the extensive literature on Facebook and MySpace a comparison of findings concerning the adoption of these two SNSs by students might serve as an obvious example. This paper might act as a starting point for such comparative cross-literature research.

\section{Enterprise Social Networking: Implications and Outlook}

The above-presented analysis has revealed existing ISN research in some selected key areas (e.g., privacy, personal impression management etc.). However, while some findings are certainly useful, transferring results from the public Internet to an enterprise context has to be done very carefully. Preliminary studies on enterprise use of SNSs have pointed to the fact that these are open technologies in a way that they need to be appropriated according to context-specific circumstances (Richter and Riemer 2009). SNSs and their features do not precipitate adoption and use, so that SNS usage practices and benefits are likely to be very different in an enterprise context. Hence, while the existing research on public SNS usage serves as a valuable basis and starting point, more dedicated research on SNSs in the context of Enterprise 2.0 is needed. In a professional context, benefits yielded by SNSs are likely to be very different, as some preliminary studies have shown (see above). In the following, we will highlight potentials for SNS application in three enterpriserelated contexts: 1) recruiting and professional career development, 2) relationship facilitation in distributed work contexts, and 3) business-to-customer interactions. Table 4 displays a summary of the identified potentials, as well as a selection of future research questions on aspects of enterprise social networking.

\subsection{SNSs in Recruiting and Professional Career Development}

Some initial studies have looked into the use of SNSs by business professionals for advancing their own career opportunities, as well as by businesses wanting to hire and recruit business professionals. As such, certain SNSs that cater for a professional audience, such as LinkedIn or Xing, can be viewed as marketplaces for the exchange of skills. Schaefer (2008) has shown that users on such platforms actively engage in building and maintaining a professional contact network with the aim to advance one's career opportunities; also see Thew (2008). On the other hand, as people typically disclose a range of information about themselves (Stutzman 2006), SNSs also yield significant potentials for businesses wanting to recruit new expertise. This is well-reflected in the intensive usage of such SNSs by R\&D companies (Thew 2008), which are in constant need to identify and contact people with specific skills. The use of
SNSs for this purpose is facilitated by the more or less correct self-representation people apply on these professional platforms.

More research is needed to better understand such practices and how they can be incorporated systematically in corporate human resource strategies, e.g., what renders recruiting activities in SNSs successful? On the other hand, the potential and role for professional career development, e.g., by building social capital, also need to be understood in more systematic ways. This offers ample opportunities for future research.

\subsection{SNSs for Relationship Facilitation in Distributed Work Contexts}

Complementary to the professional use of public SNSs, companies increasingly engage in setting up dedicated SNS platforms on their Intranets for facilitating internal network building. Work in contemporary organizations has been described as highly knowledge intensive (Davenport 2005; Drucker 2000), with organizations being increasingly dependent on the performance of knowledge workers, who are often involved in many different distributed projects and virtual teams (Bultje and van Wijk 1998). At the same time it has been argued that virtual collaboration in distributed setups is often precarious (Breu and Hemingway 2004; Introna 2001) leading to problems of information transfer (Davenport 2005; Steinfield et al. 2009) and hindering the emergence of necessary shared 
understanding of group matters (Riemer and Klein 2008). In this context, SNSs offer an apparent solution for facilitating the creation and maintenance of social structures containing social capital and as channels for information transfer between individuals (Burt 1992; Granovetter 1983; Steinfield et al. 2008).

However, surprisingly little (empirical) research exists in this area investigating ISN phenomena in this context. One study has shown that internal SNSs can help employees in identifying topics of mutual interest that can create a common basis for communication between distant co-workers (DiMicco and Millen 2007). Other studies have pointed to the potential of SNS usage for maintaining and extending one's social capital within the organization (DiMicco et al. 2008; Steinfield et al. 2009). For such purposes, crucial features for Intranet SNSs are said to be those that help employees in identifying potential new contacts (e.g., through searching by common interests), thereby forming valuable weak tie social capital (DiMicco et al. 2008; Farzan et al. 2009). Some businesses have been on the forefront of piloting the use of SNSs in this context, among them IBM, SAP, and Accenture (DiMicco et al. 2008; DiMicco and Millen 2007; Richter et al. 2009a; Richter and Koch 2009).

Furthermore, findings derived from public SNSs suggest that SNSs can help users to get to know and settle in to a new social environment. Hence, we can assume that new employees who join an organization should benefit tremendously from joining an existing SNS at the same time, as they can investigate, in an unobtrusive way the interests and background of their new co-workers (social searching), thereby forming the basis for shared understanding to emerge. Similarly, SNSs facilitate the search for experts on the basis of people's profiles, which can contain detailed information on skills, capabilities, project experience and interests. Thereby, social networking opens up new possibilities for skill-based staffing of knowledge-intensive projects. Existing studies however have shown that to date SNSs do not seem to yield such behaviors (Dwyer 2007; vom Brocke et al. 2009a).

Our analysis above also points to significant privacy concerns in conjunction with using SNSs. Hence, it remains to be seen whether or not (and under which circumstances) employees would be willing to disclose to the rest of the organization significant amounts of information about themselves. As profiles in this context are likely to only reflect the professional (and not private) lives of the employees, the hurdles for disclosure are likely to be lower; nevertheless more research is needed to derive a better understanding in this area.

At the same time, Skeels and Grudin (2009) have stressed the importance of building dedicated intra-firm SNSs, as employees might otherwise start using public SNSs for communication, which is not without problems (e.g., in regards to confidentiality and security). The same problem has been acknowledged in other studies as well (DiMicco et al. 2008; Farzan et al. 2009).

In conclusion, the integration of SNSs into the internal information infrastructure seems beneficial and will most likely gather increasing attention in the future. However, as a study by Richter and Riemer (2009) has shown, implementing SNSs on the Intranet is challenging as it can lead to a 'yet-another-platform' problem, whereby people are unwilling to adopt SNSs as a new medium. Their research into how IBM achieved successful diffusion of their SNS platform suggests that an essential success factor might be the incremental introduction of social networking features to already adopted platforms, thereby growing the new system from inside an existing one.

\subsection{SNSs as medium to engage with consumers}

Besides the above-discussed potentials, SNSs can also be valuable for supporting interactions with customers. In particular, some initial works point to potentials for 1) advertising (by facilitating targeted approaches and viral marketing), 2) product development (by including consumers in the design process, i.e. prosuming) (Klein et al. 2004; Klein and Totz 2004), and 3) market intelligence (by observing and analyzing the data generated by users in SNSs).

Advertising has changed in the last decade with a major influence being the loss of consumer trust in advertising (Clemons et al. 2007). Most notably, it has been shown that customers tend to vest more trust in recommendations by other customers than in messages coming from companies (Ermecke et al. 2009). Consequently, new concepts such as viral marketing and word-of-mouth gained wide-spread popularity. Today, many online services allow for users to recommend products or services to other users and businesses have set up online presences on SNSs to connect with customers and tap into their social networks by triggering them to pass on the corporate message. However, viral marketing on SNSs has not yet lived up to the high initial expectations (Clemons et al. 2007). On the other hand, research and the development of practical approaches in this field are still in their infancy.

In any case, SNSs are home to quite specialized communities of users, which opens up other opportunities as well. By observing and studying user behavior, SNSs can be used productively in the context of new product development and design. The integration of consumers into design and production activities has been described by others as the practice of prosuming (Klein and Totz 2004; Schumacher and Feurstein 2007). Prosuming in the context of SNSs thus opens up a new field of application and research, which has not been targeted sufficiently so far. Many companies have already created so-called brand pages in SNSs like Facebook. However, how these pages are being used, what potential they yield for prosuming and how (various groups of) consumers react to these attempts remains unknown. Potentials exist to create test markets, actively (maybe playfully) engage SNS users in design activities or observe the public discussions of target groups about a company's (and competitors') products. This might yield highly valuable information for the company at comparatively low cost. At the same time however, considerable risks exist, as companies must fit in with and adhere to the (often unwritten) rules of the SNS (sub) community. More research is needed to explore these issues.

Finally, SNSs show potentials for market intelligence purposes. As discussed above, on SNSs users disclose large amounts of data about themselves. While this raises privacy issues, it is at the same time a valuable source of market intelligence data, which allows companies to learn more about their customers, both on an individual level and on the level of target groups. While currently almost no literature exists on this matter, the trend towards utilizing the potential of SNSs for market intelligence can clearly be ob- 
served in industry. ${ }^{9}$ Practice-oriented literature further substantiates this observation (Ahonen and Moore 2005; Berkman 2008). This application is fuelled by the fact that most SNSs offer APIs, which allow companies to tap into and harvest customer data in a (semi-)automated way.

\section{Conclusion and Outlook}

We have presented the results of a comprehensive literature review on the state of Internet social networking (ISN) research, with a focus on Social network sites (SNSs). To this end, we have identified four dominant strands of research, which together provide an overview of those issues that have been well researched in recent years. At the same time we identified opportunities for further research. In particular, we have shown that research to date is rather fragmented and does not yet facilitate a general understanding of the phenomenon. In particular research is very much skewed towards certain user groups (e.g., students) and platforms (in particular Facebook). More comparative research is needed taking stock of the existing body of research.

Further, we discussed implications of SNSs application in a corporate context. We differentiated between three contexts of application and discussed SNS potentials, implications of existing ISN research and future research opportunities. As such, our research ties in with the larger research and application field of Enterprise 2.0, a field which is only just emerging.

Our research has certain limitations. First of all we have focused our analysis of ISN on SNSs. With that we have omitted research on web sites that exhibit some form of ISN (such as Youtube or Flickr), but are not strictly SNSs. Hence our perspective is restricted and certain phenomena that have - at least by now - only been observed on such sites are not considered. Future research should widen the scope based on the presented literature sample in order to include such research. Moreover researching the formation of social networks on SNSs by way of social network analysis might add understanding to the body of knowledge, especially concerning the role of network position and structure. Furthermore, our literature review is journal-based. While we have included major AIS conferences, as well as those conference articles listed in the literature collection by Danah Boyd, a good part of relevant research might have been published in conferences only, since the research field is still rather young.

We hope that our analysis can contribute both to creating a research agenda for developing a better understanding of the phenomenon of ISN and to making available the current state of ISN research for the wider Enterprise 2.0 community. After all, Enterprise 2.0 phenomena are likely to become even more relevant over the next few years, since today's youth is growing up with the new technologies and have already included various social software in their daily life routines, to an extent that today's workforce, on average, does not possess (Vie 2008). Almost inevitably, mediated socializing will become even more important in the future (Boyd 2007) and today's enterprises and managers are well advised to get in contact with this new medium and try to understand it in order to utilize this new technology and its aligning culture.

\section{References}

Acquisti A, Gross R (2006) Imagined communities: awareness, information sharing, and privacy on the Facebook. Lecture Notes in Computer Science 4258:36-58

Ahonen TT, Moore A (2005) Communities dominate brands. Futuretext, London

Avram G (2006) At the crossroads of knowledge management and social software. Electronic Journal of Knowledge Management 4(1):1-10

Bächle M (2006) Social Software. InformatikSpektrum 29(2):121-124

Barnes SB (2006) A privacy paradox: social networking in the United States. First Monday $11(9)$

Beer D (2008) Social network(ing) sites...revisiting the story so far: a response to Danah Boyd \& Nicole Ellison. Journal of Computer-Mediated Communication 13(2):516-529

Berkman R (2008) The art of strategic listening: finding market intelligence through blogs and other social media. Paramount, Ithaca

Boyd D (2006a) Friends, Friendsters, and MySpace Top 8: writing community into being on social network sites. First Monday $11(12)$

Boyd D (2006b) The significance of social software. In: Burg TN, Schmidt J (eds) Blogtalks reloaded: social software research \& cases. Books on Demand, Norderstedt
Boyd D (2007) Why youth (heart) social network sites: the role of networked publics in teenage social life. In: Buckingham D (ed) Teenage social life. Youth, identity and digital media. MIT Press, New York, pp 119-142

Boyd D, Ellison N (2007) Social network sites: definition, history, and scholarship. Journal of Computer-Mediated Communication 13(1):210-230

Boyd D, Heer J (2006) Profiles as conversation: networked identity performance on Friendster. In: Proc Hawai'i international conference on system sciences (HICSS-39). Kauai

Breu K, Hemingway CJ (2004) Making organisations virtual: the hidden cost of distributed teams. J Inform Technol 19(3):191202

British Office of Communication (2008) Social networking - a quantitative and qualitative research report into attitute, behaviours and use. http://www.ofcom.org.uk/advice/ media_literacy/medlitpub/medlitpubrss/ socialnetworking/. Accessed 2010-11-08

Buffardi LE, Campbell WK (2008) Narcissism and social networking web sites. Pers Soc Psychol B 34(10):1303-1304

Bultje R, van Wijk J (1998) Taxonomy of virtual organisations, based on definitions, characteristics and typology. VoNet Newsletter 2(3):7-21

Bumgarner BA (2007) You have been poked: exploring the uses and gratifications of Facebook among emerging adults. First Monday 12(11)

Burt RS (1992) Structural holes: the social structure of competition. Harvard University Press, Cambridge

Byrne DN (2007) Public discourse community concerns, and civic engagement: exploring black social networking traditions on blackplanet.com. Journal of ComputerMediated Communication 13(1):319-340

Carroll KS (2008) Puerto Rican language use on MySpace.com. Centro Journal 20(1):96111

Carton L, Wellman B (1999) Studying on-line social networks. In: Jones S (ed) Doing internet research: critical issues and methods for examining the net. Sage, Thousand Oaks, pp 75-105

Choi JH (2006) Living in CyWorld: Contextualising cy-ties in South Korea. In: Bruns A, Jacobs J (eds) Use of blogs (digital formation). Peter Lang, New York, pp 173-186

Christofides E, Muise A, Desmarais S (2009) Information disclosure and control on Facebook: are they two sides of the same coin or two different processes? Cyberpsychology \& Behavior 12(3):341-345

Chun $\mathrm{H}$, Kwak H, Eom YH, Ahn YY, Moon S, Jeong $\mathrm{H}$ (2008) Comparison of online social relations in volume vs interaction: a case study of CyWorld. In: Proc 8th ACM SIGCOMM conference on internet measurement, pp 57-70

Clemons EK, Barnett S, Appadurai A (2007) The future of advertising and the value of social network websites: some preliminary examinations. In: Proc 9th international conference on electronic commerce. Minneapolis, pp 267-276

Davenport TH (2005) Thinking for a living. Harvard University Press, Boston

\footnotetext{
${ }_{9}^{9}$ J.D. Power: http://www.jdpowerwebintelligence.com/, http://www.aepweb.org/summit/09_Presentations/Mining_Social_Media.ppt. Outsell: http://www.outsellinc.com/store/products/541. Xtract: http://www.xtract.com/social-intelligence/. ADTelligence: http://www.adtelligence.de/de/ consulting/new-market-intelligence.
} 


\section{Abstract}

Daniel Richter, Kai Riemer, Jan vom Brocke

\section{Internet Social Networking}

\section{Research State of the Art and} Implications for Enterprise $\mathbf{2 . 0}$

An overview of the literature on Internet social networking (ISN) is presented. The authors identify four dominant streams of research and review the key contributions to the field. The review reveals that the research field is fragmented and does not yet facilitate a general understanding of the phenomenon. In particular research is very much skewed towards certain user groups (e.g., students) and platforms (in particular Facebook). Further, implications for a corporate context are discussed. In doing so, three contexts of application are differentiated: Social network sites (SNSs) for 1) recruiting and professional career development, 2) relationship facilitation in distributed work contexts, and 3) interactions with end customers. The authors discuss SNS potentials, implications of existing ISN research and future research opportunities. In summary, they seek to contribute to a better understanding of the phenomenon of ISN and to making available the current state of ISN research for the wider Enterprise $2.0 \mathrm{com}$ munity.

Keywords: Enterprise 2.0, Internet social networking, Social software
Davenport TH (2008) Enterprise 2.0: The new new knowledge management? http:// discussionleader.hbsp.com/davenport/ 2008/02/enterprise_20_the_new_new know_1.html. Accessed 2010-11-08

DiMicco J, Millen DR, Geyer W, Dugan C, Brownholtz B, Muller M (2008) Motivations for social networking at work. In: Proc ACM 2008 conference on computer supported cooperative work. San Diego, pp 711-720

DiMicco JM, Millen DR (2007) Identity management: multiple presentations of self in Facebook. In: Proc 2007 international ACM conference on supporting group work. New York, pp 383-386

Donath J, Boyd D (2004) Public displays of connection. BT Technol J 22(4):71-82

Drucker PF (2000) Knowledge-worker productivity: the biggest challenge. Calif Manage Rev 41(2):79-94

Dwyer C (2007) Digital relationships in the 'MySpace' generation: results from a qualitative study. In: Proc Hawai'i internationa conference on system sciences (HICSS-40). Waikoloa, pp 317-326

Ermecke R, Mayrhofer P, Wagner S (2009) Agents of diffusion - insights from a survey of Facebook users. In: Proc Hawai'i international conference on system sciences (HICSS-42). Waikoloa, pp 1-10

Evans DC, Gosling SD, Carroll A (2008) What elements of an online social networking profile predict target-rater agreement in personality impressions? In: Proc International conference on weblogs and social media. Seattle, pp 1-6

Farzan R, DiMicco JM, Brownholtz B (2009) Spreading the honey: a system for maintaining an online community. In: Proc ACM 2009 international conference on supporting group work. Sanibel Island, pp 31-40

Fogg B, lizawa D (2008) Online persuasion in Facebook and Mixi: a cross-cultural comparison. Lecture Notes in Computer Science 5033:35-46

Fono D, Raynes-Goldie K (2006) Hyperfriends and beyond: friendship and social norms on LiveJournal. In: Consalvo M, Haythornthwaite C (eds) Selected papers from the Association of Internet Researchers conference 2005. Peter Lang, New York, pp 91104

Goffman E (1959) The presentation of self in everyday life. Anchor, New York

Gosling SD, Gaddis S, Vazire S (2007) Personality impressions based on Facebook profiles. In: Proc international conference on weblogs and social media. Boulder, pp 2628

Granovetter M (1983) The strength of weak ties: a network theory revisited. Sociol Theor 1:201-233

Gross R Acquisti A (2005) Information revelation and privacy in online social networks (the Facebook case). In: Proc 2005 ACM workshop on privacy in the electronic society. Alexandria, pp 71-80

Groß T, Koch M (2007) Computer-Supported Cooperative Work. Oldenbourg, München

Hinduja S, Patchin JW (2008) Personal information of adolescents on the internet: a quantitative content analysis of MySpace. J Adolescence 31(1):125-146

Hippner $H$ (2006) Bedeutung, Anwendungen und Einsatzpotentiale von Social Software. HMD - Praxis der WIRTSCHAFTSINFORMATIK 43(252):6-16

Introna LD (2001) Recognising the limits of virtual organizations. In: Hunt B, Barnes S (eds) E-commerce and v-business. Butterworth-Heinemann, Oxford, pp 268-278
Jones S, Millermaier S, Goya-Martinez M, Schuler J (2008) Whose space is MySpace? A content analysis of MySpace profiles. First Monday $13(9)$

Klein S, Köhne F, Totz C (2004) Extending customer's roles in eCommerce - promises, challenges and some findings. In: Shaw MJ (ed) Electronic commerce and the digital economy. Sharpe, Armonk

Klein S, Totz C (2004) Prosumers as service configurators - vision, status and future requirements. In: Preissl $\mathrm{B}$, Bouwman $\mathrm{H}$, Steinfield C (eds) E-life after the dot com bust. Physica, Heidelberg, pp 119-135

Koch M, Richter A (2007) Enterprise 2.0: Planung, Einführung und erfolgreicher Einsatz von Social Software in Unternehmen. Oldenbourg, München

Krasnova H, Hildebrand T, Günther O, Kovrigin A, Nowobilska A (2008) Why participate in an online social network? An empirical analysis. In: Proc 16th European conference on information systems. Galway, pp 21242135

Lampe C, Ellison N, Steinfield C (2006) A face(book) in the crowd: social searching vs. social browsing. In: Proc 2006 20th anniversary conference on computer supported cooperative work. Banff, pp 167170

Lampe C, Ellison N, Steinfield C (2007) A familiar face(book): profile elements as signals in an online social network. In: Proc SIGCHI conference on human factors in computing systems. New York, pp 435-444

Lee A, Bruckman A (2007) Judging you by the company you keep: dating on social networking sites. In: Proc 2007 international ACM conference on supporting group work. Sanibel Island, pp 371-378

Lenhart A, Madden M (2007) Social networking websites and teens: an overview. http://www.pewinternet.org/PPF/r/198/ report_display.asp. Accessed 2010-11-08

Lewis K, Kaufman J, Christakis N (2008) The taste for privacy: an analysis of college student privacy settings in an online social network. Journal of Computer-Mediated Communication 14(1):79-100

Livingstone S (2008) Taking risky opportunities in youthful content creation: teenagers' use of social networking sites for intimacy, privacy and self-expression. New Media \& Society 10(3):393-411

McAfee A (2006a) Enterprise 2.0, version 2.0. http://blog.hbs.edu/faculty/amcafee/index. php/faculty amcafee_v3/enterprise_20 version_20\%.Accessed 2010-11-08

McAfee AP (2006b) Enterprise 2.0: the dawn of emergent collaboration. MIT Sloan Management Review 47(3):21-28

Newman MEJ (2003) The structure and function of complex networks. Siam Review 45(2):167-256

O'Reilly T (2005) What is Web 2.0? http:// www.oreillynet.com/pub/a/oreilly/tim/ news/2005/09/30/what-is-web-20.html. Accessed 2010-11-08

Raacke J, Bonds-Raacke J (2008) MySpace and Facebook: applying the uses and gratifications theory to exploring friendnetworking sites. Cyberpsychology \& Behavior 11(2):169-174

Richter A, Kneifel D, Ott F (2009a) Fallstudie: Social Networking bei Accenture. Wirtschaftsinformatik \& Management 1(1):78-

Richter A, Koch M (2009) Zum Einsatz von Social Networking Services im Unternehmen. In: Proc Internationale Konferenz Wirtschaftsinformatik. Vienna, pp 851-860 
Richter A, Koch $M$, Jahnke I, Bullinger A, Stocker A, Graz KC (2009b) Tagungsband zum Workshop: Enterprise 2.0-Web $2.0 \mathrm{im}$ Unternehmen. Logos, Berlin

Richter A, Riemer K (2009) Corporate social networking sites - modes of use and appropriation through co-evolution. In: Proc ACIS international conference on computer and information science. Melbourne, pp 722-732

Richter D, Riemer K, vom Brocke J, Große Böckmann S (2009c) Internet social networking - distinguishing phenomenon and practical manifestation. In: Proc 17th European conference on information systems. Verona, pp 2603-2614

Riemer K, Klein S (2008) Is the v-form the next generation organisation? An analysis of challenges, pitfalls and remedies of ICT-enabled virtual organisations based on social capital theory. J Inform Technol 23(3):147-162

Rosen C (2007) Virtual friendship and the new narcissism. The New Atlantis 17(1):15-31

Schaefer C (2008) Motivations and usage patterns on social network sites. In: Proc 16th European conference on information systems. Galway, pp 2088-2099

Schumacher J, Feurstein K (2007) Living Labs - the user as co-creator. In: Proc 13th international conference on intelligent communities for Europe. Lingen, pp 27-32

Session LF (2009) "You looked better on MySpace". Deception and authenticity on the Web 2.0. First Monday 14(7)

Skeels MM, Grudin J (2009) When social networks cross boundaries: a case study of workplace use of Facebook and Linkedln In: Proc ACM 2009 international conference on supporting group work. Sanibel Island, pp 95-104

Steinfield C, DiMicco JM, Ellison N, Lampe C (2009) Bowling online: social networking and social capital within the organization In: Proc fourth international conference on communities and technologies. University Park, pp 245-254

Steinfield C, Ellison NB, Lampe C (2008) Social capital, self-esteem, and use of online social network sites: a longitudinal analysis. J Appl Dev Psychol 29(6):434-445

Stutzman F (2006) An evaluation of identitysharing behavior in social network communities. Journal of the International Digital Media and Arts Association 3(1):10-18

Thew D (2008) Linkedln - a user's perspective: using new channels for effective business networking. Business Information Review 25(2):87-90

Tong ST, Van der Heide B, Langwell L, Walther JB (2008) Too much of a good thing? The relationship between number of friends and interpersonal impressions on Facebook. Journal of Computer-Mediated Communication 13(3):531-549

Tufekci Z (2008) Can you see me now? Audience and disclosure regulation in online social network sites. B. Sci Technol Soc 28(1):20-36

Vie S (2008) Digital Divide 2.0: "generation $\mathrm{M}^{\prime \prime}$ and online social networking sites in the composition classroom. Media Convergence 25(1):9-23 vom Brocke J, Richter D, Riemer K (2009a) Motives for using social network sites (SNSs) - an analysis of SNS adoption among students. In: Proc 22nd Bled eConference. Bled, pp 40-56

vom Brocke J, Simons A, Niehaves B, Riemer K, Plattfaut R, Cleven A (2009b) Reconstructing the giant: on the importance of rigour in documenting the literature search process. In: Proc 17th European conference on information systems. Verona, pp 32263238

Walther JB, Van Der Heide B, Hamel LM, Shulman HC (2009) Self-generated versus other-generated statements and impressions in computer-mediated communication: a test of warranting theory using Facebook. Commun Res 36(2):229-253

Walther JB, Van Der Heide B, Kim SY, Westerman D, Tong ST (2008) The role of friends' appearance and behavior on evaluations of individuals on Facebook: are we known by the company we keep? Hum Commun Res 34(1):28-49

Wasserman S, Faust K (1994) Social network analysis: methods and applications. Cambridge University Press, Cambridge

Ybarra ML, Mitchell KJ (2008) How risky are social networking sites? A comparison of places online where youth sexual solicitation and harassment occurs. Pediatrics 121(2):350-357

Zhao S, Grasmuck S, Martin J (2008) Identity construction on Facebook: digital empowerment in anchored relationships. Comput Hum Behav 24(5):1816-1836 


\section{Internet Social Networking}

Research State of the Art and Implications for Enterprise 2.0

Daniel Richter, Kai Riemer, Jan vom Brocke

Business \& Information System Engineering (2011) 3(2)

Appendix (available online via http://springerlink.com) 
The timeframe for our literature review comprises the years 2003 to 2009. The first starting point (cf. Fig. A-1) for the identification of literature was the literature review by Danah Boyd and Nicole Ellison (2007), as well as an associated literature list, which Danah Boyd is maintaining on her website ${ }^{1}$. We have not neglected conference publications that appeared in the literature list for our literature review, despite the general focus on journal publications. We did so as (1): The research field is still young and hence only a limited amount of literature does exist. (2): The literature list by Danah Boyd is, to our knowledge, the most important listing of publications in the field. Hence listed publications are accessible to a wide audience but moreover probably known to most researchers in the field and therefore most likely have a relevant impact.

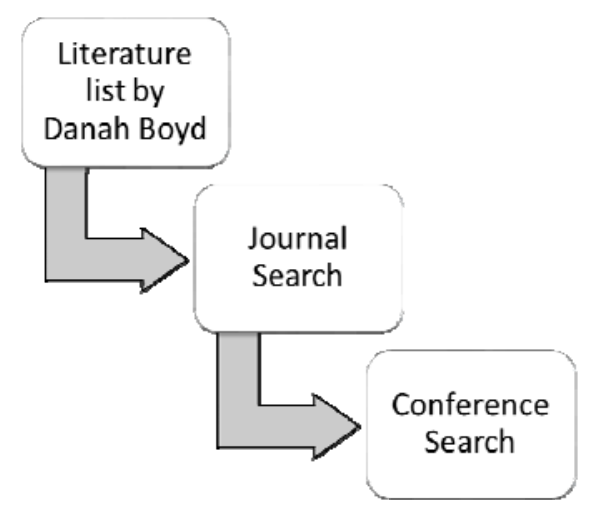

Abb. A-1 Search process

In the next step we carried out a full literature search on every journal that appeared in this literature list. Moreover, we included the main journals in the field of Information Systems (specifically those included in the "AIS senior scholars' basket of eight"). An overview of all journals that are covered in our literature review can be found in Tab. A-1. Furthermore we included the proceedings of the main International and European Conferences (ICIS and ECIS).

Tab- A-2 ${ }^{2}$ provides an overview of the databases we did search. Further the URL, search phrases, search options, number of relevant articles found and number of used articles ${ }^{3}$ are listed. If possible we did search the full-text articles, for all databases we searched the abstracts. In general we searched for the terms Social Network Site, Social Network Service and Social Networking as closed terms. Depending on the search engine we used different means for concatenation. Further we also searched by our search phrases as open terms (without concatenation) in the Journals included in the AIS Senior Scholars' basket of eight and later manually identified the topic and whether or not to include these publications in the review process.

\footnotetext{
${ }^{1}$ http://www.danah.org/researchBibs/sns.html

${ }^{2}$ Publications that were already listed in the literature list by Danah Boyd only appear in that column and not again in that of the respective Journal

${ }^{3}$ Paper that deal with ISN in a broader sense, e.g. on other websites (like weblogs), technical design issues of SNSs or Social Network Analysis were excluded.
} 
Tab. A-1 Journals included in the literature review

\begin{tabular}{|c|c|c|}
\hline$\#$ & Journal & Database \\
\hline 1 & AIS Transactions on Human-Computer Interaction & AIS Library \\
\hline 2 & Communications of the Association for Information Systems & AIS Library \\
\hline 3 & Journal of Information Technology Theory and Application & AIS Library \\
\hline 4 & Journal of the Association for Information Systems & AIS Library \\
\hline 5 & Management Information Systems Quarterly & AIS Library \\
\hline 6 & Pacific Asia Journal of the Association for Information Systems & AIS Library \\
\hline 7 & Scandinavian Journal of Information Systems & AIS Library \\
\hline 8 & Information Systems Journal & AIS Library \\
\hline 9 & MISQ Executive & AIS Library \\
\hline 10 & Electronic Markets & Springer Link \\
\hline 11 & Lecture Notes in Computer Science & Springer Link \\
\hline 12 & ACM Computing Surveys (CSUR) & ACM Digital Library \\
\hline 13 & ACM Journal of Computer Documentation (JCD) & ACM Digital Library \\
\hline 14 & ACM Journal on Emerging Technologies in Computig Systems (JETC) & ACM Digital Library \\
\hline 15 & Journal of Data and Information Quality (JDIQ) & ACM Digital Library \\
\hline 16 & Journal of Experimental Algorithmics (JEA) & ACM Digital Library \\
\hline 17 & Journal of the ACM (JACM) & ACM Digital Library \\
\hline 18 & Journal on Computing and Cultural Heritage $(\mathrm{JOCCH})$ & ACM Digital Library \\
\hline 19 & Journal on Educational Resources in Computing (JERIC) & ACM Digital Library \\
\hline 20 & ACM Inroads & ACM Digital Library \\
\hline 21 & Communications of the ACM & ACM Digital Library \\
\hline 22 & Computers in Entertainment (CIE) & ACM Digital Library \\
\hline 23 & ACM Transactions Journals & ACM Digital Library \\
\hline 24 & First Monday & Journal Homepage \\
\hline 25 & Journal of Computer-Mediated Communication & Journal Homepage \\
\hline 26 & CyperPsychology \& Behaviour & Journal Homepage \\
\hline 27 & Computer in Human Behaviour & Journal Homepage \\
\hline 28 & Journal of Absolescent Research & Journal Homepage \\
\hline 29 & Information, Communication \& Society & Journal Homepage \\
\hline 30 & Computer and Composition & Journal Homepage \\
\hline 31 & Communication Research & Journal Homepage \\
\hline 32 & Archieve of Pediatrics \& Adolescent Medicine & Journal Homepage \\
\hline 33 & European Journal of Information Systems & Palgrave \\
\hline 34 & Journal of Information Technology & Palgrave \\
\hline 35 & Information Systems Research & Journal Homepage \\
\hline 36 & Journal of Management Information Systems & Journal Homepage \\
\hline 37 & The Journal of Strategic Information Systems & Science Direct \\
\hline
\end{tabular}


Tab. A-2 Databases used in the search process

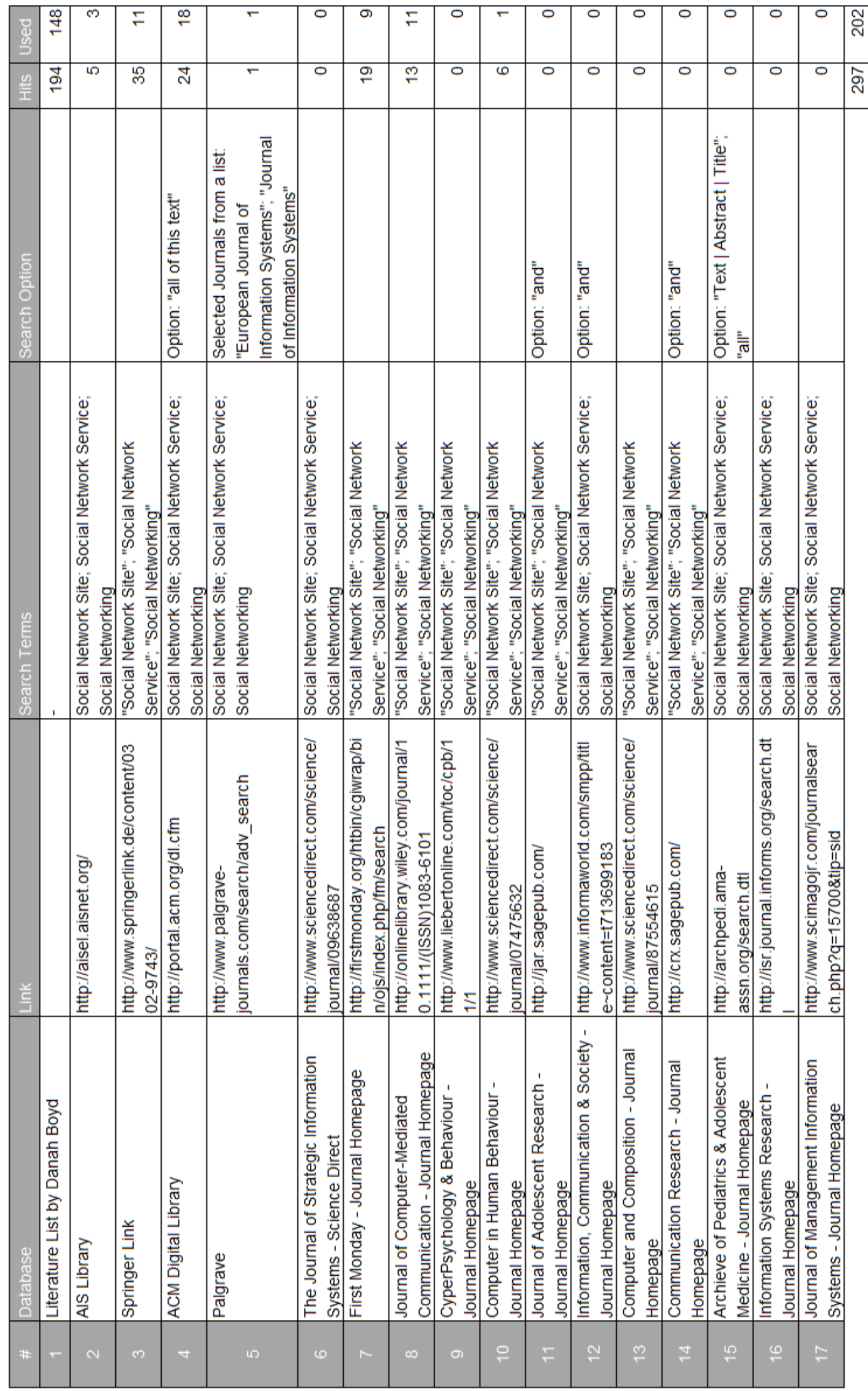

